\title{
MAPPING OF HEALTH FACILITIES IN JIMETA METROPOLIS: A DIGITAL APPROACH
}

\author{
EZRA ENOCH ALHAMDU AND LUKMAN A. SANUSI
}

(Received 07 July 2010; Revision Accepted 11 November 2014)

\begin{abstract}
In planning for any suitable development in any field, the primary requirement is the relevant data and maps. This is one of the major problems hindering the proper planning and monitoring of the various health facilities located in Jimeta metropolis. Survey techniques -were employed for the acquisition of data, GPS was used to pick the coordinates of the various health centres. Two sets of data were acquired and used, cartographic data and attribute data. Scanning was carried out using CorelDraw!2 while Georeferencing and Digitizing was done using ILWIS3.1 academic Software packages. A digital map, showing the spatial distribution of health facilities in Jimeta metropolis was produced; this is more accurate than the conventional hand-drawn maps. Computer technology and the use of GIS should be extended to facilitate man-power development and to achieve the required objectives of planning and monitoring facilities easily.
\end{abstract}

\section{INTRODUCTION}

Health facilities in Nigeria have remained a matter of considerable importance to successive governments since independent in 1960. Health represents one of the most basic human needs and has no doubt a profound impact on the welfare and productivity of the individuals, hence attempt were made by three ties of government to provide adequate health facilities particularly at the grass root to meet the aspiration of the general public. These developments were however hampered through inadequate planning due to lack of plans and maps to show the location of these facilities.

Attempts were made in the past by the YolaNorth Local Government Primary Health Care Department to acquire the map showing locations of various health facilities, the attempt was short-lived due to either finance or manpower. The ministry of land and survey which is the body saddle with the responsibility of providing maps and plans are hampered by lack of adequate modern digital equipment's and power produce such maps. Most of their equipment are outdated and can not cope up with present technological development of providing digital maps of the health facilities required by the local government.

The ministry of health is responsible for overseeing the health facilities in the state; they also plan and monitor the distribution drugs and other facilities for the efficient management of the health centers. However, planning and effective monitoring of these facilities is hampered by lack of plans or maps showing the distribution. Attempts were made during the military regime to produce the map of all the health facilities in Adamawa State, covering the 21 Local government areas. The programme failed because of lack of commitment on the part of thegovernment to finance the project, and lack of continuity on the civilian administration to continue with the programme.
This research paper is aimed at demonstrating the proper method that can be employed in developing a digital map of the health facilities and also to highlight some of the problems that would be encountered. This would be achieved by taking the coordinates of the various health centers, Georeferencing and Digitization of the analogue map of Jimeta obtained from the ministry of land and survey.

Digital mapping has now become an indispensable tool in solving many environmental problems. The existence of the list health centers does not give room for planning, but the knowledge of their spatial distribution will assist in planning and monitoring.

Most people do not understand the necessity of maps for development until when the need arise; a good base map will aid proper distribution of amenities. The result of a well distribution planned pattern of settlement and distribution of services is the handwork of availability of up-to date topographic and cadastral maps. Obansa and Suleiman (1997). GIS is capable of acquiring spatially indexed data from a variety of sources, changing the data into useful formats, storing the data, retrieving and manipulating the data for analysis, and generating the output required by the user.

A digital computer provides the basis for storage, manipulation and display of large amounts of data that have been encoded in digital form. Dug gal, (2004). The present development in electronics and computer capabilities has revolutionized surveying and mapping practice; digital representations and calculations of physical measurements are highlyaccurate and consistent. Digital method of map production makes it easier to avoid mistakes and inaccuracies in handling results of measurements and for keeping records. N.K. Ndukwe (2001).

Mussa and Tukur (2006) wee able to produce digital map of Basic Education Schools in Adamawa, using satellites images (Remote Sensing) and GIS. The map produced was more accurate and cartographically

Ezra Enoch Alhamdu, Department of Surveying and Geoinformatics. Federal University of Technology Yola. Adamawa State, Nigeria.

Lukman A. Sanusi, Department of Surveying and Geoinformatics. Federal University of Technology Yola. Adamawa State, Nigeria. 
superior to the hand-drawn maps.

M. H. Sani (2008) designed and created digital database of the secondary schools in Bauchi. The research was able to produce a digital map, and also crated a database for all the facilities found in these secondary schools. He efficiently demonstrated the application of Geographical Information System (GIS) in digital mapping technology.

Dan Fulani, E. (2007) produce a digital of Jalingo, showing the location of educational institution; the researcher employed the Geographical Information System to demonstrate the use of digital mapping technology. The map produced was cartographically superior to the hand-drown map.

Digital mapping is an off-shoot if modern computer technology and the main objective is for the computer to take over most of the task that are normally performed by human operations in conventional mapping process to quicken map production. Ndukwe (2001).

Digital mapping of the health facilities in Jimeta metropolis of Yola-North Local Government Area was never a time carried out. The fact is that the need of such map still persists is clear manifestation of the eminence of the problem, hence the necessity of embarking on this research study.

\section{METHODOLOGY}

Data: GPS coordinates of Primary Health Centres and Clinics (Including Private Clinics)

Map of Jimeta metropolis showing street and road

Software: CorelDraw 12 Package Integrated Land and water Information system (ILWIS) 3.1 Academic GIS and RS Package.

Hardware: Laptop Computer (Pentium R1.66 GHz Dual Core Intel Processor, HDD 120GB, 1014 MB Ram)

GPS (Global Positioning System).

Scanner (HPF430 DeskJet all in one series).

Printer (HP DeskJet D1460)

\section{DATA ACQUISITIONS: \\ Data collection:}

Data Collection is the primary operation in Digital mapping operation. The primary sources of data were the GPS coordinates, which are observed in both latitude and longitude in UTM coordinate system. Two sets of data were acquired and used in this work, cartographic (Map or Geographic) data and attribute data. The attribute data was gathered from the respective health centers. Thus both spatial and nonspatial data were obtained from the field.

\section{Data Processing:}

The primary aim of establishing GIS is to capture, convert, store and analyze data. The source of the data, (analogue data) is the hardcopy base map of Yola- North, these was capture, converted and stored in digital format using digitizer. In order to use digital data in ILWIS requires importing the files and changing them to ILWIS file format. Importing was done with import module, in which the import format was selected and imported via the geo-gateway referred to as the universal to import format. Before importing files into ILWIS the data type should be known, either it is appoint, segment or polygon or raster map, and the type of information stored inside the map. The analogue may was converted to digital map. Hardcopy map lay on board of the scanner. Scanned image was exported into a folder named Alhamdu on the desktop using TIFF (Tagged Image File Format). ILWIS Software, Import/Map module activated, the image was selected for Georeferencing.

\section{Geo-Referencing:}

Geo-referencing refers to the location of layer or courage in space as defined by known coordinate reference system, such as UTM rectangular grid coordinates $(x, y)$ or geographical coordinate; latitude and longitude $(<p X)$. The ILWIS software was open, and the file/create/geo-referencing module activated, a dialogue box appear, JimetaCoord was typed as Georeference name and performed starting with $x$ coordinate then $y$ - coordinate in anticlockwise direction when finished a sigma value of 0.471 of 0.471 is noticed which is quite acceptable.

\section{Digitizing Point/Segment Map:}

A point map was created; the location of the health facilities/centres and roundabout were digitized. A segment map was also created; the road network consisting of major and minor roads in Jimeta and water bodies (i.e. Lake Gerio and River Benue) were digitized.

Form the digitized maps, the segment map containing road network, bridge and water bodies. The point map i.e. clinics and roundabout. The layers were divided into classes. The digitized layer for road network was opened, the add layer tool was used to overlay other layers to give the required output.

\section{RESULT AND DISCUSSION The Digital Map}

A map has a primary content (the main theme of map), a secondary content (roads, contours etc) and a supportive content (legend, scale, north arrow etc. These various data layer are combined into a single map to produce a map depicting desired features. The Jimeta map produced has coordinate system on which the map was registered in the Universal Traverse Mercator Projection System (UTM). The digital map produced, provides an efficient way mapping large area. GPS facilities the creation of digital map of Jimeta using GIS. The health facilities of Jimeta metropolis were shown as occupying same positions with reference to the major and minor roads. Thus, all the health centres are accessible base on their locations.

The map shows the spatial distribution of health facilities/centres in Jimeta metropolis, in which the locations of health centres are depicted. Itis also important to note that these health facilities are not distributed equally base on the wards in Jimeta. Their location follow similar pattern, i.e. they are located either on the main streets or minor roads within Jimeta metropolis (Yola-North Local Government).

\section{CONCLUSION}

A good base map provides all the necessary information required for distribution of amenities; the 
result of well planned pattern of settlement and distribution of services is based on availability of an update map. The may will serve as a guide for locating health facilities across the local government in relation to their position to the major and minor roads. The map produce will be of assistance for decision making on health related issues and it will be of great benefit to those seeking medical attention to know where the centres are located and which of them has the required facilities to meet up with then" demands (standard).

The research work, apart from providing the means of digital keeping records of health facilities, it has demonstrated how GIS could be employed in manipulating spatial data for decision making and consequently for the development of health facilities in the local government. The digital map produced, has some qualities in term of accuracy and standard more than hand-drown maps.

\section{RECOMMENDATION}

Computer technology ${ }^{7}$ and its application is globally accepted as the most convenient means of capturing, storing, processing, analyzing and presentation of information for decision making.

\section{MAPPING OF HEALTH FACILITIES IN JIMETA METROPOLIS: A DIGITAL APPROACH}

TABLE 1: NON-SPATIAL DATA FOR HEALTH FACILITIES IN YOLA-NORTH L.G.A

\begin{tabular}{|c|c|c|c|c|c|c|c|}
\hline S/No & Name of Health Centre & $\begin{array}{l}\text { No. of } \\
\text { Doctors }\end{array}$ & $\begin{array}{lr}\text { No. } & \text { of } \\
\text { Trained Staff }\end{array}$ & $\begin{array}{l}\text { No. of Untrained } \\
\text { Staff }\end{array}$ & No. of Beds & UTM (Northing) & UTM (Easting) \\
\hline 1. & Haske Clinic Jambutu & 1 & 3 & 4 & 6 & 1027694 & 0216685 \\
\hline 2. & Gerio Mat. Centre & 3 & 5 & 2 & 7 & 1027557 & 0217174 \\
\hline 3. & $\begin{array}{lll}\begin{array}{l}\text { Ibrahim } \\
\text { Hospital }\end{array} & \text { Alfa } & \text { Mem. }\end{array}$ & 2 & 8 & 5 & 18 & 1025911 & 0216826 \\
\hline 4. & ARHYEL Royal Hospital & 3 & 8 & 10 & 30 & 1025291 & 0216210 \\
\hline 5. & Airfaroce Clinic & 4 & 15 & 6 & 22 & 1025992 & 0217981 \\
\hline 6. & Bekaji Clinic & Nil & 9 & 3 & 22 & 1024551 & 0218668 \\
\hline 7. & Boshong Clinic & 1 & 6 & 5 & 12 & 1024382 & 0218861 \\
\hline 8. & Matco Clinic & 3 & 9 & 30 & 30 & 1022463 & 0220252 \\
\hline 9. & Police Clinic & 2 & 15 & 5 & 20 & 1024635 & 0220223 \\
\hline 10. & Freedom Polyclinic & 3 & 17 & 20 & 20 & 1025336 & 0220140 \\
\hline 11. & Gal-Bose Hospital & 4 & 27 & 21 & 40 & 1025202 & 0220432 \\
\hline$\overline{12 .}$ & Triump Clinic Ltd. & 3 & 10 & 3 & 11 & 1026186 & 0220067 \\
\hline 13. & Peace Hospital & 5 & 25 & 15 & 20 & 1026059 & 0219191 \\
\hline 14. & Jimeta Clinic & 4 & 18 & 12 & 14 & 1026239 & 0219631 \\
\hline 15. & Specialist Hospital & 32 & 210 & 340 & 10 & 1026513 & 0219433 \\
\hline 16. & Bamaiyi Hospital & 2 & 8 & 4 & 10 & 1026996 & 0219915 \\
\hline
\end{tabular}




\begin{tabular}{|c|c|c|c|c|c|c|c|}
\hline$\overline{17 .}$ & Mercyland Clinic & 1 & 8 & 4 & 12 & 1027503 & 0218009 \\
\hline 18. & Jambutu PHC & Nil & 10 & 6 & 8 & 1027412 & 0217695 \\
\hline 19. & Sauki Clinic & 2 & 10 & 6 & 16 & 1026492 & 0218310 \\
\hline 20. & Yelwa Clinic & Nil & 9 & 6 & 12 & 1026858 & 0220212 \\
\hline 21. & A. A.M.D Clinic & Nil & 6 & 3 & 12 & 1027222 & 022048 \\
\hline 22. & Ajiya Health Clinic & Nil & 8 & 4 & 15 & 1026602 & 0220833 \\
\hline 23. & $\begin{array}{l}\text { Gambo Jimeta Health } \\
\text { Clinic }\end{array}$ & Nil & 6 & 3 & 11 & 1027181 & 0220853 \\
\hline 24. & $\begin{array}{l}\text { AbdullahiYakubuMem. } \\
\text { Clinic }\end{array}$ & Nil & 8 & 4 & 12 & 1026522 & 0221275 \\
\hline 25. & $\begin{array}{l}\text { AtikuAbubakar Health } \\
\text { Centre }\end{array}$ & Nil & 8 & 3 & 15 & 1025466 & 0220675 \\
\hline 26. & Dawa'u Clinic & 2 & 10 & 9 & 39 & 1024950 & 0220675 \\
\hline 27. & Major Aminu Urban & Nil & 7 & 6 & 9 & 1027351 & 0219679 \\
\hline
\end{tabular}

Each local government should as a matter of necessity have the digital map, showing the spatial location of the health facilities.

The digital may will assist the general public to know which of the centres are equipped and which would re quire expansion of facilities based on demand from the general public.

It is also recommended that staff should be trained on the use computer technology for efficient planning and monitoring of the health facilities in the local government.

It is also recommended that the local government should be encourage to establish a database using the digital map, so that inventory of both drugs and manpower should be in the database, this will assist in monitoring the distribution of staff and drugs to the various health centres.

\section{REFERENCE}

Adeoye, A. A., 1998. Geographic/Land Information System. Principles and Applications. Omoniyi Printing Press, Lagos Nigeria.

Danfulani, E., 2007. GIS Application to Education Facilities in Jalingo, Taraba State. An unpublished Degree Thesis of the Department of Surveying and Geoinformatics, 2007.
Darryl, T. and Mathew Z., 2000. GPS/GIS Supporting Water Resource Management. http:/gisesri.com/library/user,conf.

Duggal, S. K., 2004. Surveying, Vol.2, $2^{\text {nd }}$ Edition Tara McGraw-Hill, New York, ESRI, (20G5) History of ESRI.Httpi/wvvw^esri.com/company/about/histor y.htinl

Ezra, P. H and Sunday, O. S. O., 2006. A tool in the hand of a Digital Map Maker, OKE International Ventures Kaduna.

Kufoniyi, O., 2001. "Impacting National Economic Base through Spatial Infrastructure" $36^{\text {th }}$ A.G.M of NIS.

Lipping, W. and Jerson R., 2002. The Role of Webbased GIS in Water Utilities: National: http:/gisesri.com/library/user.conf.

Mohammed, J.S., 2008. Management of Learning Facilities in Secondary Schools within Bauchi Metropolis using GIS. M.Tech. ResearchProject, Unpublished, 2008.

Musa, A. A and Tukur, A. L., 2006. Applying Remote Sensing and GTS for the mapping of Basic Educational Schools in Adamawa State. 
Ndukwe K, Ndukwe., 2001. Digital Technology in Surveying Mapping: Principles, Application and Legislative Issues, RhyceKarex Publishers 2001.

Rober, C. Sandra E. and John S., 1999. Creating a Water Utility GIS from Aquifer up.

Uzair, S. and Bruce F., 2000. Arc View Application in Storm Water and Wastewater Management. 